\title{
CARACTERIZAÇÃO QUÍMICA PRELIMINAR E MORFOLOGIA SUPERFICIAL DE GRÃOS DETRÍTICOS: ILMENITAS KIMBERLIITICAS DE COROMANDEL, METAMÓRFICAS DE ALUVIÕES DO RIO JEQUITINHONHA E GRANÍTICAS DE GALILÉIA, MINAS GERAIS
}

\author{
JOÃO EDUARDO ADDAD ${ }^{1}$, MAXIMILIANO MARTINS ${ }^{2} \&$ RICARDO SCHOLZ ${ }^{2}$
}

\begin{abstract}
RESUMO Grãos de ilmenita de concentrados aluvionares diamantíferos de áreas kimberlíticas em Coromandel, oeste de Minas Gerais, paleocascalhos diamantíferos de camadas basais do rio Jequitinhonha em Terra Branca, norte de Minas Gerais e depósitos aluvionares de áreas graníticas em Galiléia, nordeste de Minas Gerais, foram analisadas para comparação entre $\mathrm{Cr}, \mathrm{Mg}, \mathrm{Fe}, \mathrm{Ti}, \mathrm{Al}, \mathrm{Mn}, \mathrm{Ca}$, Ta e $\mathrm{Nb}$, com microssonda eletrônica. Procedimentos de microscopia eletrônica de varredura foram utilizados para a descrição textural das superfícies dos grãos. Os resultados mostraram a variação característica de $\mathrm{Mg}$ e $\mathrm{Cr}$ e níveis discriminantes de $\mathrm{Al}, \mathrm{Ti}, \mathrm{Fe}$ e $\mathrm{Mn}$. As ilmenitas de Coromandel se apresentaram como picroilmenitas. Valores de $\mathrm{Al} \mathrm{em} \mathrm{Coromandel} \mathrm{foram} \mathrm{intermediários} \mathrm{para} \mathrm{as} \mathrm{outras} \mathrm{duas} \mathrm{fontes,} \mathrm{enquanto} \mathrm{que} \mathrm{Ti,} \mathrm{Fe} \mathrm{e} \mathrm{Mn} \mathrm{mostraram} \mathrm{habilidades}$ diferenciadoras entre os grãos de Coromandel e as outras proveniências. Ilmenitas de Coromandel apresentaram superfícies com intercrescimentos ilmenita-perovskita, enquanto que ilmenitas de Terra Branca e Galiléia não mostraram texturas específicas. Composição e textura superficial se apresentaram discriminantes para as ilmenitas kimberlíticas.
\end{abstract}

Palavras-chave: ilmenite, picroilmenita, Coromandel, Jequitinhonha, diamante

\begin{abstract}
PRELIMINARY CHEMICAL CHARACTERIZATIONAND SURFACE MORPHOLOGY OF DETRITAL GRAINS: KIMBERLITIC ILMENITES FROM COROMANDEL, METAMORPHIC ILMENITES FROM ALLUVIAL DEPOSITS OF THE JEQUITINHONHA RIVER AND GRANITIC ILMENITES FROM GALILÉIA, MINAS GERAIS, BRASIL Ilmenite grains from alluvial diamondiferous concentrates from kimberlitic areas at Coromandel, W of Minas Gerais, diamondiferous paleogravels from the basal beds of Jequitinhonha river at Terra Branca, $\mathrm{N}$ of Minas Gerais, and alluvial deposits from granitic occurrences, at Galiléia, $\mathrm{NE}$ of Minas Gerais, were analyzed to obtain comparative data of $\mathrm{Cr}$, $\mathrm{Mg}$, Fe, $\mathrm{Ti}$, Al, Mn, Ca, Ta and Nb, with electron micropobe. SEM procedures were run to describe texturally the grains surfaces. The results showed the characteristic variation of $\mathrm{Mg}$ and $\mathrm{Cr}$, and discriminating levels of $\mathrm{Al}, \mathrm{Ti}, \mathrm{Fe}$ and $\mathrm{Mn}$. The ilmenites from Coromandel were found to be picroilmenites. All values at Coromandel were intermediate between the other two sources, while Ti, Fe and Mn showed differentiation capabilities between Coromandel grains and one of the other provenances. Ilmenites from Coromandel presented surface with ilmenite-perovskite intergrowths whilst ilmenites form Terra Branca and Galiléia do not have specific textures. Composition and surface texture were discriminant for the kimberlitic ilmenites.
\end{abstract}

Keywords: ilmenite, picroilmenite, Coromandel, Jequitinhonha, diamond

Grãos de ilmenita ocorrem em grande parte das areias pela sua alta resistência física e química. A variação química de grãos de ilmenita encontradas em sedimentos apresenta um potencial para determinação de proveniências e mistura de fontes, por este mineral ser composicionalmente sensível ao ambiente formador, incorporando desde elementos traço até componentes majoritários em proporções diversas. Ilmenitas são consideradas indicadores para rochas kimberlíticas quando apresentam determinadas características composicionais, como altos teores de magnésio e cromo, e texturais, tais como capas de reação secundária de intercrescimentos ilmenita-perovskita.

Com objetivo de fornecer dados comparativos para $\mathrm{Cr}, \mathrm{Mg}$ e outros elementos, dez grãos de ilmenita provenientes de concentrados aluvionares diamantíferos, coletados em drenagens de uma área com ocorrências kimberlíticas da região de Coromandel, oeste de Minas Gerais (localização exata não fornecida pelo grupo prospector), dez grãos coletados em concentrados obtidos a partir de paleocascalheiras diamantíferas de porções basais do leito do rio Jequitinhonha em Terra Branca, consideradas como provenientes de metamorfitos, e dez grãos separados a partir de sedimentos coletados em trechos de drenagens que dissecam restritamente áreas de ocorrência de granitóides em Galiléia, leste de Minas Gerais, foram analisados texturalmente, com auxílio de um microscópio eletrônico de varredura, modelo JEOL $840 \mathrm{~A}$ e quimicamente, por microssonda eletrônica, modelo JEOL - JXA8900R, no Laboratório de Microanálises, Instituto de Ciências Exatas, UFMG, para os elementos ferro, titânio, magnésio, cromo, alumínio, manganês, cálcio, tálio e nióbio, na forma de porcentagem em peso de óxidos.

O tamanho médio dos grãos é de: 2-3 mm em Coromandel, 1-2 $\mathrm{mm}$ em Terra Branca e 1-2 $\mathrm{mm}$ em Galiléia. As análises foram efetuadas em cinco pontos em cada grão, com descarte de resultados originados em anomalias composicionais devido a intercrescimentos e inclusões de óxidos de ferro. Porções periféricas com leucoxênio, trilhas de óxidos de ferro e capas de ilmenita+perovskita também foram evitados na escolha dos grãos/pontos para análise. Considerando o potencial de diferenciação entre ilmenitas kimberlíticas e outras ilmenitas, os resultados mostraram a variação característica entre magnésio e cromo, além de diferenças nos teores de alumínio, titânio, ferro e manganês. Mesmo considerando o limite de detecção da microssonda eletrônica em $0,10 \%$ em peso, os valores abaixo deste limite foram relacionados por se tratar de uma análise 
conjunta dos grãos e pela presença de valores mais altos para os elementos selecionados, evidenciando o contraste de teores conforme a amostra. Nióbio não mostrou padrões discriminantes, com valores distribuídos entre 0,14 e $0,31 \%$, enquanto cálcio e tálio mantiveram valores sempre abaixo do limite de confiabilidade de análise e foram descartados.

Os teores de óxidos de magnésio e cromo discriminaram claramente as ilmenitas kimberlíticas das outras ocorrências, estando dentro da faixa composicional típica para esta fonte, entre 4 e $15 \%$ de $\mathrm{MgO}$ e até $2 \%$ de $\mathrm{Cr}_{2} \mathrm{O}_{3}$, caracterizando-as como picroilmenitas. Os valores de alumínio das amostras de Coromandel foram intermediários para as duas outras fontes. Os outros óxidos mostraram possibilidades de discriminação entre os grãos de origem kimberlítica e uma das outras proveniências. Valores de titânio para as ilmenitas de Coromandel apresentaram sobreposição às ilmenitas graníticas, enquanto que permaneceram separados das ilmenitas metamórficas por, pelo menos, 5 pontos percentuais. Os valores de ferro total e manganês mantiveram sobreposição entre as ilmenitas de Coromandel e de Terra Branca, mas mostraram um incremento discriminante para as amostras provenientes de Galiléia.

Texturalmente, as ilmenitas de Coromandel mostraram a presença de capas superficiais de ilmenita-perovskita, desde graus de integridade elevados (Fig. 1), indicando transporte limitado a partir da área fonte, até a quase eliminação por abrasão sedimentar (Fig. 2) em pontos de coleta mais distantes ( 10 quilômetros).

As capas de ilmenita+perovskita apresentaram aspecto rugoso (Fig. 3 e 4), se alterando para uma cobertura texturizada de leucoxênio (Fig. 5). Ao contrário das alterações usuais de leucoxênio de ilmenitas de outras proveniências (i.e. graníticas), as capas secundárias formadas a partir de ilmenitaperovskita dos grãos kimberlíticos, se quebram mais facilmente, expondo o interior inalterado a partir de fraturas conchoidais, aspecto observado nas Figuras 6 e 7. As ilmenitas de Terra Branca e Galiléia apresentaram superfícies com aspecto rugoso a liso, sem a presença de texturas especílicas. Tanto a comparação química quanto a textural foram discriminantes para as ilmenitas de origem kimberlíticas.

Considera-se ainda que as análises comparativas de alumínio, titânio, ferro e manganês foram auxiliares na discriminação entre fontes distintas, possibilitando uma melhor caracterização da proveniência de ilmenitas detríticas.

Agradecimentos Os autores agradecem à Fapemig e ao CNPq, pelos auxílios concedidos, e ao Laboratório de Microanálises, Instituto de Ciências Exatas, UFMG, pelas análises efetuadas. A dois revisores anônimos da RBG pelas sugestões ao manuscrito.

Manuscrito NB-28 Recebido en 15 de novembro de 2001 Revisão dos autores em05 de dezembro de 2001 Revisão accita em07 de dezembro de 2001

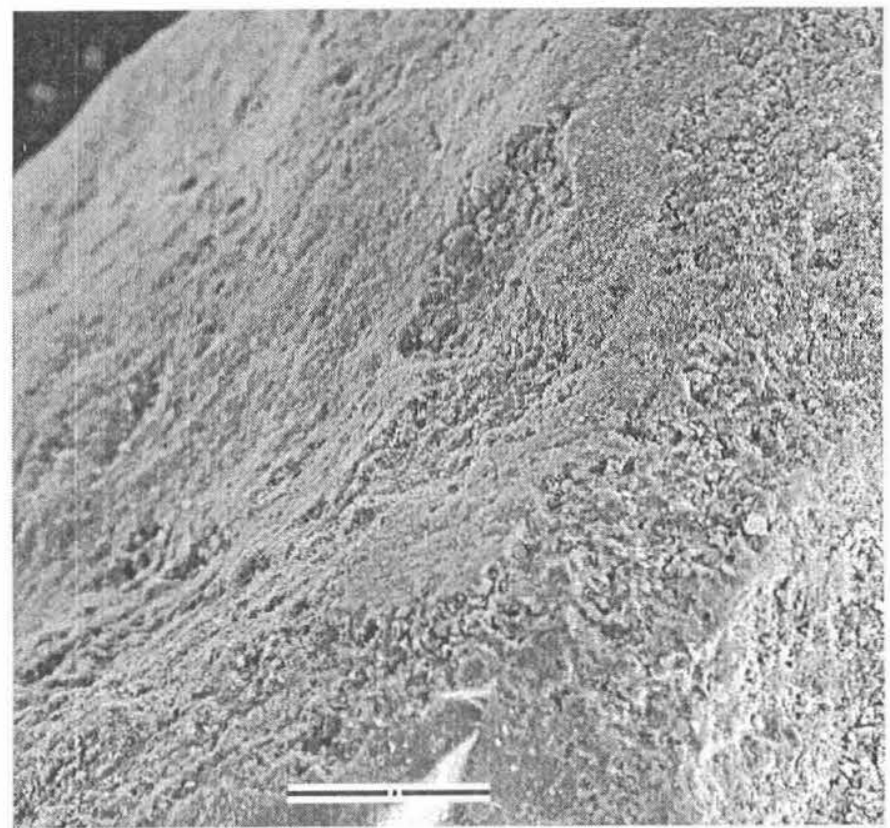

Figura 2 - Superficie alisada de picroilmenita de Coromadel. Imagem obtida com MEV, barra com 0, Imm de comprimento.
Figura I - Textura superficial de ilmenita-perovskita em picroilmenita de Coromadel. Imagem obtida com MEV, barra com 0,1 mm de comprimento. 


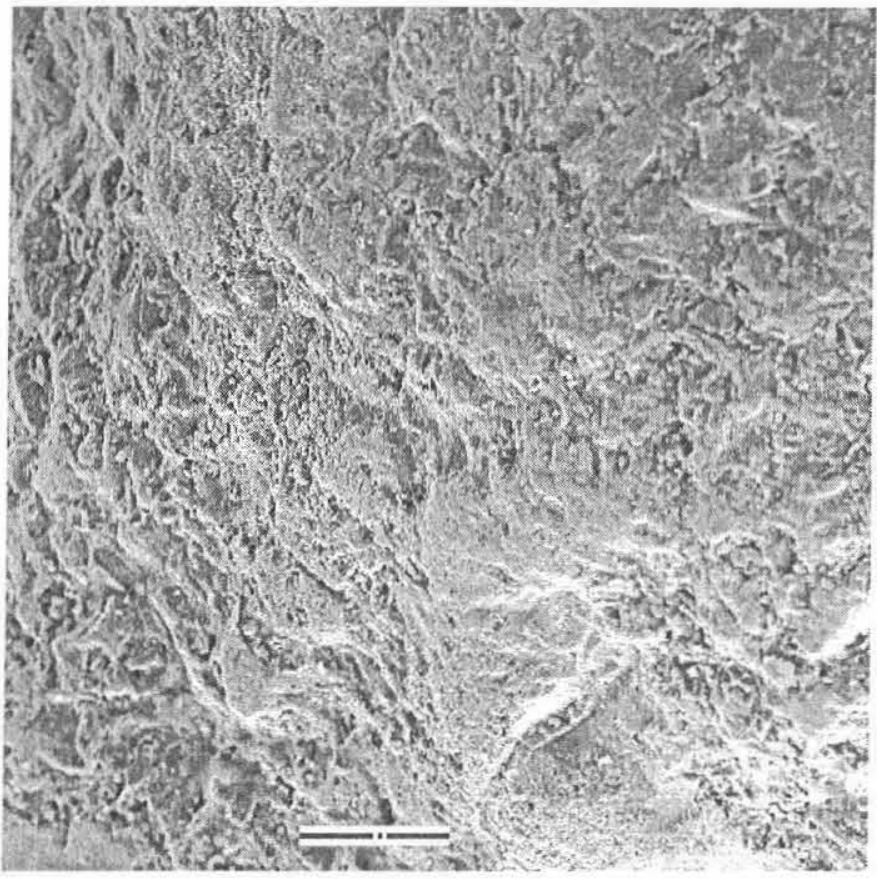

Figura 3 - Textura superficial de ilmenita-perovskita em picroilmenita de Coromadel. Imagem obtida com MEV, barra com $0,1 \mathrm{~mm}$ de comprimento.

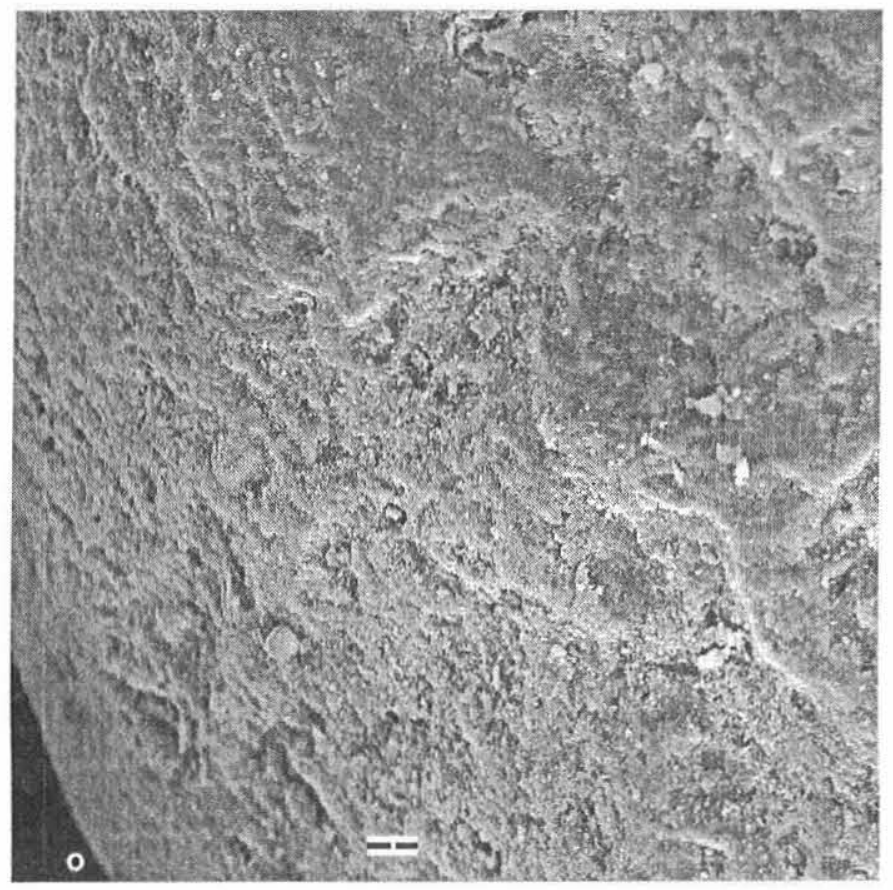

Figura 4 - Textura superficial de ilmenita-perovskita em picroilmenita de Coromandel. Imagem obtida com MEV, barra com $0,1 \mathrm{~mm}$ de comprimento.

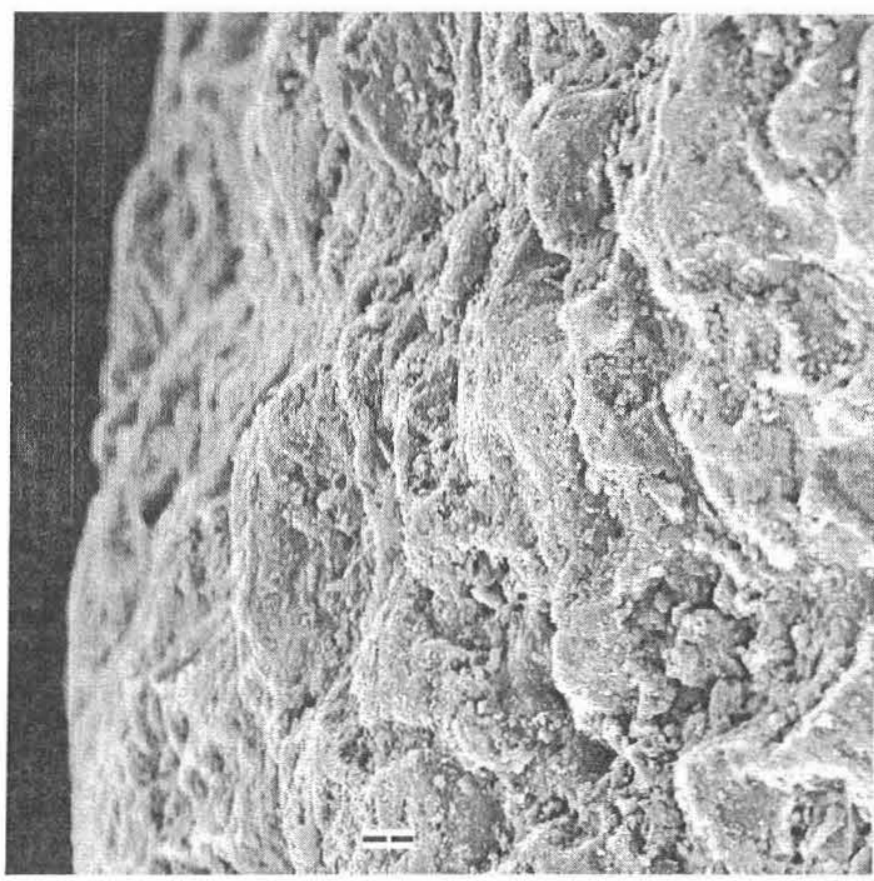

Figura 5 - Textura superficial de ilmenita-perovskita em picroilmenita de Coromadel, com alto grau de rugosidade. Imagem obtida com MEV, barra com $0,1 \mathrm{~mm}$ de comprimento.

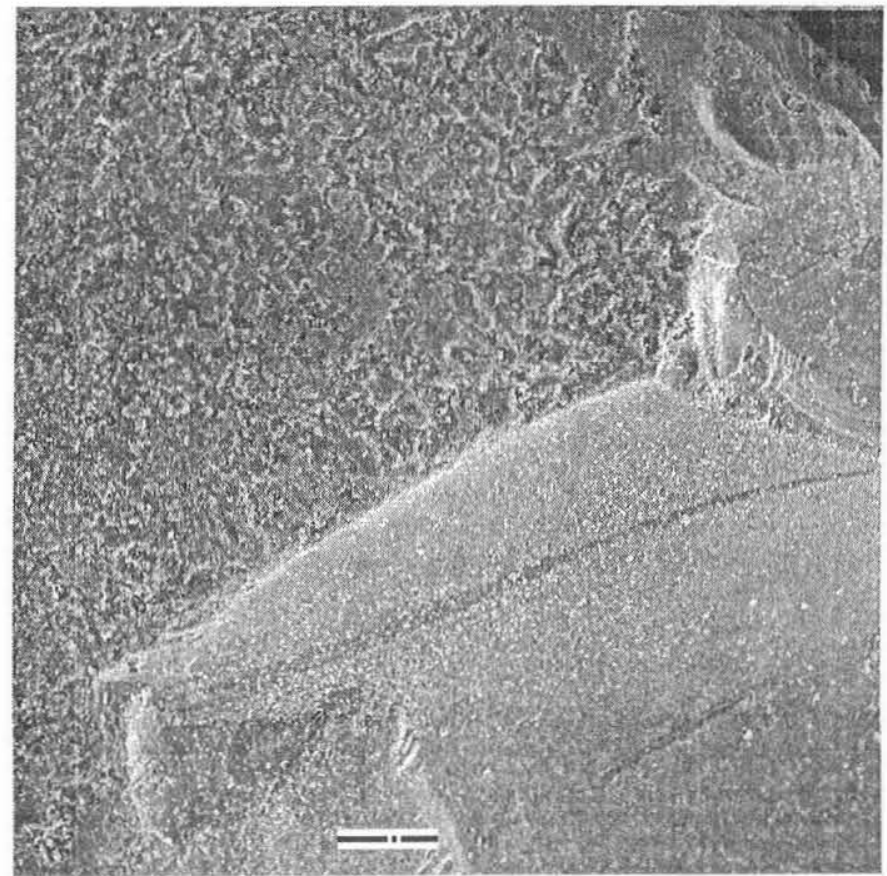

Figura 6 - Fraturamento conchoidal com eliminação de textura superficial ilmenita-perovskita e exposição de porções internas em picroilmenita de Coromandel. Imagem obtida com $M E V$, barra com $0,1 \mathrm{~mm}$ de comprimento. 
Tabela I - Resultados de análise química de grãos de ilmenita detrítica, em valores máximos e mínimos de porcentagens em peso de óxidos para Coromandel, Terra Branca e Galiléia, obtidos por microssonda eletrônica (limite de detecção: 0,10\% em peso).

\begin{tabular}{|c|c|c|c|c|c|c|}
\hline Óxidos & $\begin{array}{c}\text { Coromandel } \\
\text { máximo }\end{array}$ & $\begin{array}{c}\text { Coromandel } \\
\text { minimo }\end{array}$ & $\begin{array}{c}\text { Terra Branca } \\
\text { máximo }\end{array}$ & $\begin{array}{c}\text { Terra Branca } \\
\text { minimo }\end{array}$ & $\begin{array}{c}\text { Galiléia } \\
\text { máximo }\end{array}$ & $\begin{array}{c}\text { Galiléia } \\
\text { minimo }\end{array}$ \\
\hline $\mathrm{TiO}_{2}$ & 50,89 & 46,79 & 60,67 & 55,02 & 51,91 & 49,73 \\
\hline${ }^{*} \mathrm{Fe}_{2} \mathrm{O}_{3}$ & 38,73 & 34,35 & 36,89 & 30,15 & 46,46 & 41,76 \\
\hline $\mathrm{MgO}$ & 11,52 & 9,59 & 0,71 & 0,21 & 0,09 & 0,02 \\
\hline $\mathrm{Cr}_{2} \mathrm{O}_{3}$ & 2,02 & 0,81 & 0,01 & não detectado & 0,08 & não detectado \\
\hline $\mathrm{MnO}$ & 0,47 & 0,35 & 0,96 & 0,20 & 4,29 & 1,42 \\
\hline $\mathrm{Al}_{2} \mathrm{O}_{3}$ & 0,15 & 0,06 & 0,29 & 0,16 & 0,04 & não detectado \\
\hline
\end{tabular}

* Considerado como Fe total

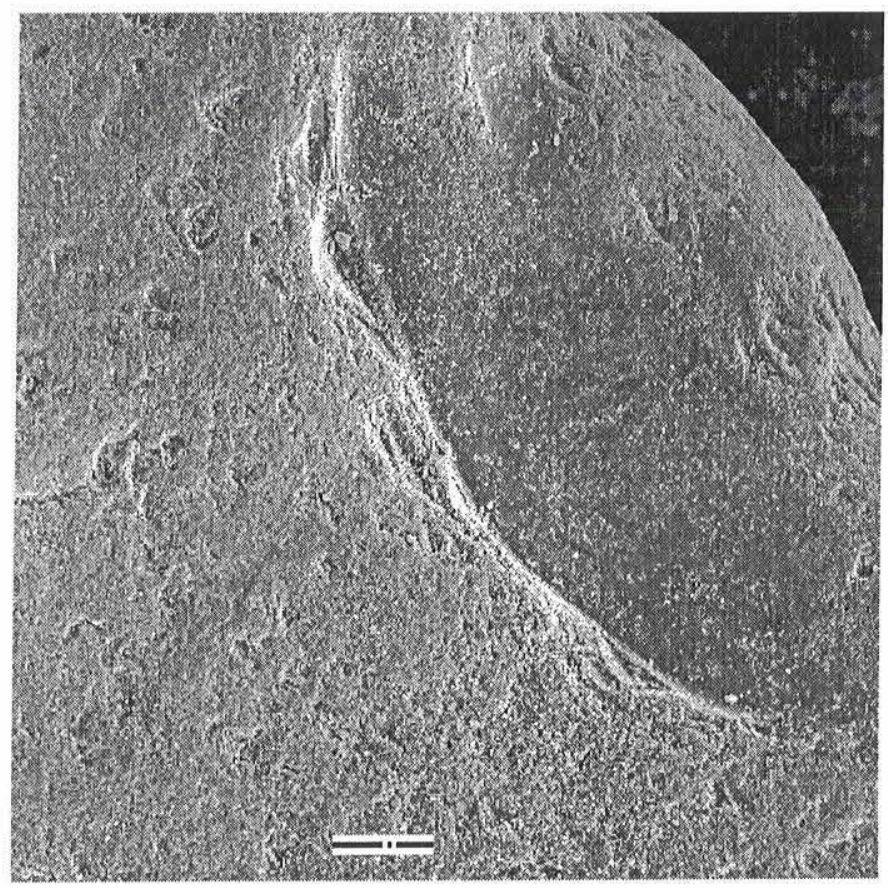

Figura 7 - Fraturamento conchoidal com eliminação de textura superficial ilmenita-perovskita e exposição de porções internas em picroilmenita de Coromadel. Imagem obtida com $M E V$, barra com 0, Imm de comprimento. 